\title{
A RESERVA DO POSSÍVEL E O PAPEL DO JUDICIÁRIO NA EFETIVIDADE DOS DIREITOS SOCIAIS
}

\author{
Airton Ribeiro da Silva ${ }^{1}$ \\ Fabrício Pinto Weiblen ${ }^{2}$
}

\begin{abstract}
RESUMO: O presente estudo se propõe a analisar questões referentes ao princípio da reserva do possível como limitador das prestações estatais, bem como, a partir de apontamentos da doutrina, apresentar reflexões acerca da intervenção do Judiciário em impasses que esbarram na escassez de recursos. Dessa forma, estuda a sujeição de medidas de política social à disponibilidade de recursos e a competência do Judiciário em dispor sobre prestações positivas.
\end{abstract}

PALAVRAS-CHAVE: reserva do possível, direitos sociais, direitos de segunda geração, competência do Judiciário.

The possible reserve and the role of the Judiciary in the effectivity of the social rights.

ABSTRACT: The present study intends to analyze questions that refer to the possible reserve principle as a limit to State prestations and also, through remarks of the doctrine, present reflections about the Judiciary's intervention in disputes that stumble in the lack of resources. This way, it studies the subjection of social policy measures to the disposability of resources and the competence of the Judiciary to resolve about positive prestations.

KEY-WORDS: possible reserve, social rights, second generation rights, competence of the Judiciary.

\section{INTRODUÇÃO}

Após um longo período de ditadura militar, no qual direitos eram lesados e a sociedade vivia sob a sombra da censura e da tortura, a Constituição de 1988 surgiu como o marco de uma nova era de democracia, voltada aos direitos do cidadão. A nova Carta deu atenção especial à consolidação dos direitos fundamentais, de forma a assegurar garantias básicas à pessoa, proporcionando uma vida digna à população.

Desde então, tornaram-se maiores os anseios pela efetivação de direitos, assim como se popularizou a procura pelo Judiciário. Em conseqüência, à medida que a busca pela prestação estatal cresceu, a disponibilidade de meios econômicos para tal se revelou insuficiente.

Assim, a escassez de recursos se tornou fato impeditivo da satisfação dos anseios de todos e o princípio da reserva do possível passou a ser freqüentemente utilizado

\footnotetext{
${ }^{1}$ Advogado, Mestrando em Direito, Cidadania e Desenvolvimento na Unijuí. E-mail: airtonribeirosilva@hotmail.com.

${ }^{2}$ Acadêmico do Curso de Direito da UFSM. E-mail: fabriciopw @ terra.com.br.
}

ISSN - 1981-3694

(c) 2007. Departamento de Direito da UFSM. Todos os direitos reservados. 
como argumento limitador das prestações estatais, mormente no que tange aos direitos sociais. Nesse cenário, surgem certas indagações, tais como: os direitos sociais têm aplicabilidade imediata? É válido o argumento da falta de recursos? Quando? Pode o Judiciário intervir de modo a garantir uma prestação positiva do Estado, apesar da falta de meios econômicos? Que critérios utilizar para uma decisão que favorece a uns em detrimento de outros?

Diante disso, o presente estudo tem por escopo fazer uma análise do impasse entre o princípio da reserva do possível e a efetividade dos direitos sociais, bem como tratar acerca do papel do Judiciário em tal questão. Para tanto, o artigo será dividido em quatro partes. Primeiramente, será feita uma abordagem dos aspectos referentes aos direitos sociais, inseridos na teoria das "gerações" de direitos. Em um segundo momento, serão analisados alguns apontamentos sobre o surgimento e a aplicação do princípio da reserva do possível. Em seguida, far-se-á um estudo do papel do Judiciário na efetivação dos direitos sociais prestacionais e seus limites e, por fim, tentar-se-á trazer algumas breves considerações finais, bem como perspectivas acerca da matéria.

\section{DIREITOS SOCIAIS E SUA APLICABILIDADE}

No decorrer da história, há uma alteração contínua no conteúdo dos direitos humanos, onde novos anseios são transformados em direitos para acolher necessidades que se tornaram mais intensas (AMARAL, 2001, p.100). Esse movimento, chamado de "gerações" de direitos, consiste em verdadeiras dimensões dos direitos, como preleciona Paulo Bonavides (1997, p.518), uma vez que a mudança não se dá apenas com o nascimento de outras formas de amparo, mas também com a releitura dos direitos e garantias já antes adotados. Tais direitos não se superam, mas sim coexistem.

A primeira "geração" consiste nos direitos de liberdade, surgidos como uma proteção ao poder do Monarca, até então absoluto. Posteriormente, observou-se que a proteção voltada contra o Estado não mais era suficiente, tendo em vista que havia abuso e exploração também no âmbito privado. Dessa forma, foram reconhecidos os chamados direitos de segunda "geração", ou direitos sociais, aqueles voltados contra a opressão do homem em face do próprio homem.

Assim, enquanto os direitos de liberdade exigem, para sua efetividade, uma abstenção do Estado, os direitos sociais, por outro lado, carecem da ação estatal. Bobbio (1992) traz lição esclarecedora sobre tais distinções: 
É supérfluo acrescentar que o reconhecimento dos direitos sociais suscita, além do problema da proliferação dos direitos do homem, problemas bem mais difíceis de resolver no que concerne àquela prática de que falei no início: é que a proteção destes últimos requer uma intervenção ativa do estado, que não é requerida pela proteção dos direitos de liberdade, produzindo aquela organização dos serviços públicos de onde nasceu até mesmo uma nova forma de Estado, o Estado Social. Enquanto os direitos de liberdade nascem contra o superpoder do Estado - e, portanto, com o objetivo de limitar o poder -, os direitos sociais exigem, para sua realização prática, ou seja, para a passagem da declaração puramente verbal à sua proteção efetiva, precisamente o contrário, isto é, a ampliação dos poderes do Estado. (BOBBIO, 1992, p.72).

Nesse quadro, os direitos de liberdade são freqüentemente tratados como direitos negativos, uma vez que, teoricamente, não necessitam da atuação estatal, enquanto os direitos sociais são chamados também de direitos positivos, visto que exigem uma prestação por parte do Estado. Na lição de Bonavides (1997, pp. 518-519), tem-se a separação entre direitos de liberdade, que sendo negativos, têm sede constitucional, e direitos sociais, que seriam positivos e dependeriam de meios materiais e, assim, de mediação legislativa e orçamentária.

Todavia, embora reconhecidos os direitos sociais, a real problemática reside no atinente à eficácia de tais direitos positivos. Nesse diapasão, podem-se considerar três correntes doutrinárias divergentes: aqueles que têm os direitos sociais como equivalentes aos direitos individuais, aqueles que negam eficácia aos direitos sociais, uma vez que a carga positiva depende de mediação do legislador e de meios materiais, e uma terceira, que vê os direitos sociais sujeitos à reserva do possível, visto que a concretização exige emprego de meios financeiros.

Os direitos sociais são previstos na Constituição pelas chamadas normas programáticas. Tais normas consistem em disposições que indicam os fins sociais a serem alcançados pelo Estado, tendo em vista a concretização e o cumprimento dos objetivos basilares previstos na Constituição. Em verdade, são normas vagas, com baixa efetividade social e jurídica, não gerando, em sentido estrito, direitos subjetivos públicos para a população.

Por outro lado, Andreas Krell (2002), abordando o tema, afirma:

As normas programáticas sobre direitos sociais que hoje encontramos na grande maioria dos textos constitucionais dos países europeus e latinoamericanos definem metas e finalidades, as quais o legislador ordinário deve elevar a um nível adequado de concretização. Essas "normas-programa” 
prescrevem a realização, por parte do Estado, de determinados fins e tarefas. Elas não representam meras recomendações ou preceitos morais com eficácia ético-política meramente diretiva, mas constituem Direito diretamente aplicável.(KRELL, 2002, p.20).

Com efeito, cabe indagar se um direito ainda pode ser chamado de "direito" quando o seu reconhecimento e sua real proteção são adiados por tempo indeterminado, além de confiados à vontade de sujeitos cujo comprometimento em executar um "programa" é apenas uma obrigação moral ou, no máximo, política (BOBBIO, 1992, p. 78).

A previsão de instrumentos de efetivação foi deixada em segundo plano, na medida em que o legislador apenas tratou de positivar os fins sociais de forma vaga, como se a presença no texto legal por si só bastasse. De fato, conforme afirma Keith Rosenn, considera-se como resolvido tudo que é promulgado como lei, sem devidas reflexões a respeito de sua exeqüibilidade ou eficácia. Pouca atenção é dirigida à apreciação de como as normas se comportam na prática (1998, p.54 apud KRELL, 2002, p.27).

Todavia, conforme o artigo $5^{\circ}, \S 1^{\circ}$ da Constituição de 1988 , que determina que "as normas definidoras dos direitos e garantias fundamentais têm aplicação imediata", não foi feita diferenciação no tratamento dos direitos fundamentais, sejam eles negativos ou positivos. Portanto, os direitos sociais, a princípio, teriam eficácia equivalente à das demais garantias fundamentais, e caberia ao operador do direito o dever de tornar esses direitos efetivos, através de um esforço hermenêutico inovador.

Contudo, consoante Canotilho (2001, p.431 e ss.), o postulado da aplicabilidade imediata dos direitos sociais prestacionais não pode resolver-se de acordo com a dimensão de tudo ou nada, razão pela qual o seu alcance dependerá do exame da hipótese em concreto, isto é, da norma de direito fundamental em pauta. A aplicabilidade imediata dos direitos positivos pode ser analisada apenas como uma presunção, de maneira que eventual recusa de sua aplicação deverá ser necessariamente justificada.

Segundo Ingo Wolfgang Sarlet (2000, p.157), “a inviabilidade de uma eficácia 'absoluta' e a necessidade de se adotar soluções diferenciadas decorre, em verdade também (e principalmente) da estrutura normativa e da natureza eminentemente principiológica das normas definidoras de direitos e garantias fundamentais". Porém, segundo o referido autor (2001, p.318), a problemática reside menos no grau de 
completude da norma do que no aspecto da alegada ausência de legitimação dos tribunais para a determinação do objeto e do quantum da prestação, na medida em que a decisão sobre a aplicação de recursos públicos incumbiria precipuamente ao legislador, questões que serão abordadas mais adiante.

\section{PRINCÍPIO DA RESERVA DO POSSÍVEL}

Por mais que um mandamento legal tenha sido inserido no próprio Texto Constitucional, ele somente poderá obter sua real efetividade na presença das condições fáticas e jurídicas capazes de lhe conferir esta eficácia. Caso contrário, na ausência deste contexto, por mais nobre que fosse o objetivo da norma, ninguém poderá ser obrigado a cumprir suas diretrizes. Dessa forma, a escassez de meios econômicos pode limitar a plena satisfação dos direitos sociais. Assim, a implementação destes direitos se torna dependente da existência de condições materiais que permitam sua atendibilidade.

A teoria do princípio da reserva do possível tem como origem as decisões proferidas pela Corte Constitucional Federal da Alemanha. O surgimento deste posicionamento é encontrado na apreciação de um famoso caso (BverfGE n. ${ }^{\text {3 } 33, ~ S . ~} 333$ apud KRELL, 2002, p.52), no qual uma ação judicial então proposta visava a obter uma decisão que permitisse a certo estudante cursar o ensino superior público. Tal pretensão se baseava na garantia prevista pela Lei Federal alemã de livre escolha de trabalho, ofício ou profissão, tendo em vista que não havia disponibilidade de vagas em número suficiente para todos os interessados em frequientar as universidades públicas (SARLET, 2001, n. 3). Neste caso, ficou estabelecido que só se pode exigir do Estado o atendimento de um interesse, ou a execução de uma prestação em benefício do interessado, desde que observados os limites da razoabilidade, destacando ainda a Suprema Corte Germânica que os intitulados direitos sociais “estão sujeitos à reserva do possível no sentido daquilo que o indivíduo, de maneira racional, pode esperar da sociedade" (KRELL, 2002, p.52). Tal entendimento inviabilizaria que fossem requeridas providências do Estado acima de um patamar logicamente razoável de exigências sociais, razão pela qual restou afastada a lógica de que o Poder Público estaria obrigado a disponibilizar um número ilimitado de vagas, para acolher todos os interessados em ingressar nas universidades públicas.

Em outras palavras, o Poder Judiciário, por mais que tenha como objetivo de conferir a devida aplicabilidade às normas inseridas na Carta Magna, não pode almejar 
suprir todas as carências sociais mediante a expedição de ordens judiciais, pois estas não obterão a efetividade pretendida, haja vista que faltam condições materiais suficientes para a sua concretização. Além disso, a satisfação de uns implica em negar o direito a outros, em face da escassez de recursos.

Tal fato torna-se ainda mais grave quando se trata do campo da saúde, em que uma decisão pode redundar em grande sofrimento ou mesmo em morte. Em tais hipóteses, a alegação da reserva do possível, em uma análise superficial, pode parecer cruel e desumana, mormente se visto no caso concreto. Sobre o tema, Gustavo Amaral (2001) adverte que:

Diante de um quadro como esse, a tendência natural é fugir do problema, negá-lo. Esse processo é bastante fácil nos meios judiciais. Basta observar apenas o caso concreto posto nos autos. Tomada individualmente, não há situação para a qual não haja recursos. Não há tratamento que suplante o orçamento da saúde ou, mais ainda, aos orçamentos da União, de cada um dos Estados, do Distrito Federal ou da grande maioria dos municípios. Assim, enfocando apenas o caso individual, vislumbrando apenas o custo de cinco mil reais por mês para um coquetel de remédios, ou de cento e setenta mil reais para um tratamento no exterior, não se vê a escassez de recurso, mormente se adotado o discurso de que o Estado tem recursos nem sempre bem empregados. (AMARAL, 2001, pp.146-147).

Porém, os custos de tratamento na saúde tornaram-se insustentáveis para o Estado quando tomados como um todo e, além da questão financeira, há recursos não financeiros, como órgãos, pessoal especializado e equipamentos, que são escassos em comparação com as necessidades.

Nesse quadro, tendo em vista que os direitos sociais não devem ter tratamento diferenciado de outros direitos fundamentais, mas os recursos para o atendimento das demandas são finitos, surgem os conflitos, nos quais se torna imperioso decidir sobre o emprego de recursos escassos através de escolhas disjuntivas (o atendimento de uns e o não-atendimento de outros). Tal conflito não é, em geral, tratado pela doutrina e mesmo o critério de ponderação se revela insuficiente quando se tratam de prestações positivas.

Nesses casos, "não há como prestigiar o valor hierarquicamente superior, pois a colisão pode ser entre o paciente que espera na fila para transplante apenas de rim, há mais tempo, com o que espera na recém-criada fila para transplante duplo de rim e pâncreas" (AMARAL, 2001, pp.126-127). 
Em sentido oposto, Andréas Krell (2002) afirma que o princípio da reserva do possível consiste em uma falácia, decorrente de um Direito Constitucional comparado equivocado, na medida em que a situação social brasileira não pode ser comparada àquela dos países membros da União Européia (KRELL, 2002, pp.53-54). Segundo o autor, no que diz respeito ao campo da saúde, a solução seria satisfazer todos os casos. "Se os recursos não são suficientes, deve-se retirá-los de outras áreas (transportes, fomento econômico, serviço da dívida) onde sua aplicação não está tão intimamente ligada aos direitos mais essenciais do homem: sua vida, integridade e saúde. Um relativismo nessa área poderia levar a ponderações perigosas e anti-humanistas do tipo 'por que gastar dinheiro com doentes incuráveis ou terminais?"” (KRELL, 2002, p.53).

Nesse cenário, deve ser assegurado um padrão mínimo de segurança material à população, já que o Estado Social não pode ser compelido a garantir um padrão "ótimo" de bem-estar social, mormente quando se trata de prestações estatais obtidas via judicial, mas sim a efetivar as condições para uma existência com dignidade. Porém, tal afirmação não significa que a otimização do bem-estar social não possa ser uma meta a ser alcançada.

Contudo, cumpre destacar que mesmo este patamar mínimo pode esbarrar na escassez de recursos, ou seja, há a possibilidade do limite da reserva do possível, já que também nestes casos poderá o Estado alegar e provar que não dispõe nem mesmo dos recursos para atender às exigências mínimas em saúde, educação, assistência social, segurança, etc. Em outras palavras, o seu cumprimento pode ser negado por parte do Estado somente temporariamente em virtude de uma impossibilidade material evidente e comprovável (BARROSO, 1996, p.111).

Além do enfoque na necessidade, ou essencialidade, da prestação, a excepcionalidade da situação concreta deveria ser analisada, uma vez que, por exemplo, um cataclismo, natural ou social, pode momentaneamente tornar inexigível algo que pouco antes o era. O grau de essencialidade está ligado ao mínimo existencial, à dignidade da pessoa humana e, em conseqüência, quanto mais essencial for a prestação, mais excepcional deverá ser o motivo para que ela não seja acolhida. Dessa forma, haverá uma ponderação dessas duas variáveis. Se o grau de essencialidade superar o de excepcionalidade, a prestação deve ser entregue, caso contrário, a recusa estatal será legítima (AMARAL, 2001, pp. 214 ss.). 


\section{O PAPEL DO JUDICIÁRIO NA EFETIVIDADE DOS DIREITOS SOCIAIS}

A aplicação e destinação de recursos públicos, inclusive no que tange às prioridades na esfera das políticas públicas, com reflexos diretos na questão orçamentária, é reconhecida como tarefa que cabe precipuamente ao legislador ordinário, razão pela qual há alegações de que se trata de problema de natureza competencial (SARLET, 2001, p.286).

Dessa forma, uma crítica recorrente à utilização da via judicial para a efetivação dos direitos prestacionais é a de que tal meio consistiria em uma violação ao princípio da Separação de Poderes, visto que a matéria dependeria de mediação orçamentária e, portanto, estaria dentro dos limites de competência dos Poderes Executivo e, principalmente, Legislativo.

Tal alegação ilustra o freqüente uso do princípio idealizado por Motesquieu como fundamento que dificulta cada vez mais as reivindicações sociais. Assim, o referido princípio deve também evoluir e, através de uma nova leitura necessária, poder continuar servindo ao seu objetivo inicial de assegurar os Direitos Fundamentais contra o arbítrio estatal.

Canotilho sempre viu a realização dos direitos sociais muito mais na dependência da participação política da população do que numa atuação significativa dos tribunais (1982, pp.357, 377, 429 apud KRELL, 2002, p.69). Porém, para Krell (2002), esta posição dominante no constitucionalismo alemão não é transponível para o Brasil sem as devidas alterações. Assim, "na medida em que é menor o nível de organização e atuação da sociedade civil para participar e influenciar na formação da vontade política", o que é notório na situação brasileira, "aumenta a responsabilidade dos integrantes do Poder Judiciário na concretização e no cumprimento das normas constitucionais, especialmente as que possuem uma alta carga valorativa e ideológica" (KRELL, 2002, p. 70).

Em verdade, o que se encontra no Brasil é uma oposição ao controle judicial do mérito dos atos do Poder Público, aos quais se reserva um vasto espaço de atuação autônoma, discricionária, onde as deliberações do órgão ou do agente público são definitivos quanto à sua conveniência e oportunidade. Nesse quadro, parece incorreto ignorar a realidade e se negar à possibilidade de soluções mais práticas para o bem geral em decorrência de um apego excessivo e radical ao princípio como sugerido em uma realidade passada. Assim, a invocação da teoria da Separação dos Poderes em tais 
situações é resultado de uma atitude conservadora da doutrina constitucional tradicional, a qual necessita da devida atualização de velhos dogmas, fato que se tornou imperativo em face das condições diferenciadas do moderno Estado Social (KRELL, 2002, pp.87, 90, 91).

Para Barroso (1996), o "padrão mínimo" no cumprimento das tarefas estatais poderia, sem maiores problemas, ser ordenado por parte do Judiciário, o que deixa de acontecer devido apenas a motivos ideológicos e não jurídico-racionais (BARROSO, 1996, p.155). No mesmo sentido se manifesta Sarlet (2001), ao demonstrar que, no caso da negação de prestações de serviços básicos por parte do estado, não conseguem convencer os argumentos comuns da falta de verbas e da ausência da competência do Judiciário para decidir sobre a aplicação dos recursos públicos, mormente na área da saúde, o bem maior da vida humana. Para ele, "negar ao indivíduo os recursos materiais mínimos para manutenção de sua existência pode significar, em última análise, condená-lo à morte por inanição, por falta de atendimento médico, etc." (SARLET, 2001, p.323).

Nesse diapasão, cabe ao Judiciário assumir um papel mais politizado, de forma que não apenas julgue o certo e o errado conforme a lei, mas sobretudo examine se o poder discricionário de legislar está cumprindo a sua função de implementar os resultados objetivados pelo Estado Social. Ou seja, não se atribui ao Judiciário o poder de criar políticas públicas, mas sim a responsabilidade de compelir a execução daquelas já estabelecidas nas leis constitucionais ou ordinárias. Dessa forma, exige-se um Judiciário "intervencionista" que realmente ousa controlar a falta de qualidade das prestações dos serviços básicos e exigir a concretização de políticas sociais eficientes, não podendo as decisões da Administração Pública se distanciarem dos fins almejados pela Constituição.

Seguindo esse entendimento, Krell (2002) afirma:

Num Estado Social, modelo adotado pela Carta Brasileira de 1988, o Poder Judiciário é exigido a estabelecer o sentido ou a completar o significado da legislação constitucional e ordinária que já nasce com motivações distintas às da certeza jurídica, o que o dá o papel de "legislador implícito". Dessa maneira, a agenda da igualdade redefine a relação entre os três Poderes, adjudicando ao Poder Judiciário funções de controle dos poderes políticos. (KRELL, 2002, p. 98). 
Dessa forma, na chamada "eficácia vertical" dos direitos fundamentais (SARLET, 2000, p.155), na qual os vinculados à solução de litígios que abordem os direitos e garantias fundamentais envolvendo particulares são os poderes públicos, também ao Judiciário incumbe a tarefa de conferir eficácia aos direitos sociais. A decisão sobre a aplicação dos recursos públicos, por sua direta implicação orçamentária incumbe precipuamente ao legislador, porém deve o Juiz, na medida em que entender que o critério adotado pela administração não é o ideal para o caso concreto e justificar tal entendimento, prestar a tutela imediata, de tal sorte que a as posições jurídicas fundamentais na esfera social possam ser asseguradas.

\section{CONSIDERAÇÕES FINAIS}

A situação atual da sociedade torna imperioso um novo tratamento das questões sociais. A escassez de recursos para a satisfação de todas as necessidades da população é evidente, independentemente de tratar-se de competência do legislador, do administrador ou do judiciário e, dessa forma, de suma importância são as reflexões sobre o assunto. A falta de meios econômicos traz a necessidade de uma ponderação entre a essencialidade de uma prestação e a excepcionalidade da situação, ou seja, mesmo um padrão mínimo de existência pode esbarrar na absoluta escassez de recursos materiais, mas apenas na hipótese de uma extrema excepcionalidade, visto que o tal mínimo está intimamente ligado à dignidade da pessoa humana e, portanto, é de extrema essencialidade.

No caso da existência de recursos, no qual a problemática reside na distribuição de tais recursos, é necessário que os Juízes e Tribunais, quando decidirem sobre a eficácia e efetividade das pretensões em casos específicos, fundamentem suas decisões admitindo o modo como os custos afetam a intensidade e consistência dos direitos, examinando abertamente a competição por recursos escassos que não são capazes de satisfazer a todas as necessidades sociais, implicando em escolhas que favorecem a uns em detrimento de outros. Para tanto, imprescindível ter em mente que sempre que os argumentos contra o reconhecimento dos direitos sociais como direitos subjetivos a prestações esbarrarem no bem maior da vida e da dignidade da pessoa humana, ou nas hipóteses em que, da ponderação de valores constitucionais resultar a prevalência do direito social prestacional, haverá que se reconhecer tais direitos como subjetivos e definitivos, ou seja, que possam ser buscados pela via judicial. 
Cabe ressaltar que o fim principal da Carta Política de 1988 é o de promover o bem-estar social, de modo que sejam asseguradas as condições mínimas de existência, a fim de que, a partir desse ponto, haja a possibilidade de uma otimização de tal existência. Desse modo, o argumento da falta de meios financeiros para a implementação dos direitos sociais, em regra, não deve prosperar, haja vista que estes devem ser exatamente os destinos prioritários dos recursos orçamentários. Nesse cenário, somente após a destinação de verbas para as prestações sociais caberá o debate sobre o investimento dos recursos estatais remanescentes para outros fins. Portanto, deve-se partir da presunção de que não há sujeição das medidas de política social à disponibilidade de recursos, sendo que tal presunção somente poderá ser afastada mediante justificação, diante da análise do caso concreto.

No que diz respeito ao papel essencial do Judiciário na efetivação dos direitos prestacionais, deve-se ter em mente que, face aos problemas sociais presentes no Brasil, o princípio tradicional da Separação de Poderes deve ter parâmetros e dimensões novas e diferentes daqueles das nações centrais. Exige-se cada vez mais a influência do Poder Judiciário na implementação de políticas sociais e no controle da qualidade das prestações dos serviços básicos, tendo um papel ativo na criação das condições sociais na comunidade. Em outras palavras, o Judiciário brasileiro deve se afastar do formalismo exacerbado e exercer seu importante papel no processo político da realização dos Direitos Fundamentais Sociais através da melhoria gradual dos serviços públicos básicos.

Partindo dessa premissa, uma vez não efetivados os direitos fundamentais consagrados na Carta Política pelos poderes ditos legitimados, quais sejam, Poderes Executivo e Legislativo, cabe ao Judiciário intervir, a fim de concretizar os ditames insculpidos na Constituição Federal, através de prestações positivas. Assim, ao dispor sobre as prestações estatais, o Judiciário apenas determina a realização prática da norma constitucional, não permitindo que esta se torne mera diretriz abstrata e inaplicável, ato para o qual é competente, uma vez que, no Estado de Direito, o estado soberano deve submeter-se à própria justiça que institui. Noutras palavras, não é papel do Judiciário criar novas medidas referentes a direitos sociais, o que consistiria em violação ao princípio da Separação dos Poderes, mas sim trazer uma real efetividade às políticas públicas já existentes, de modo a não permitir que um apego excessivo a formalidades acabe por obstar a concretização das metas principais do Estado Democrático de Direito. 
Por fim, cabe destacar que, se por um lado, a referida escassez de meios econômicos é um fator importante que não pode ser ignorado, por outro, não pode ser superdimensionado, tornando-se o único parâmetro a ser analisado na concretização dos direitos sociais. Assim, torna-se imperativo o acréscimo de ingredientes éticos e políticos para que o instrumental jurídico possa, não apenas ser legitimado, mas permitir que a evolução das condições econômicas e sociais possa beneficiar o maior número de pessoas.

\section{REFERÊNCIAS BIBLIOGRÁFICAS}

AMARAL, Gustavo. Direito, Escassez \& Escolha: em busca de critérios Jurídicos para lidar com a escassez de recursos e as decisões trágicas. Rio de Janeiro: Renovar, 2001.

BARROSO, Luís Roberto. O Direito Constitucional e a Efetividade de suas Normas. Rio de Janeiro: Renovar, 1996.

BOBBIO, Norberto. A Era dos Direitos. Rio de Janeiro: Campos, 1992.

BONAVIDES, Paulo. Curso de Direito Constitucional. São Paulo: Malheiros, 1997.

CANOTILHO, José Joaquim Gomes. Direito Constitucional e Teoria da Constituição. Coimbra: Livraria Almedina, 2001.

KRELL, Andreas Joachim. Direitos Sociais e Controle Judicial no Brasil e na Alemanha: os (des)caminhos de um direito constitucional "comparado". Porto Alegre: Sergio Antonio Fabris Editor, 2002.

SARLET, Ingo Wofgang. A constituição Concretizada: construindo pontes com o público e o privado. Porto Alegre: Livraria do Advogado, 2000.

Advogado, 2001.

A Eficácia dos Direitos Fundamentais. Porto Alegre: Livraria do 